\title{
The Effect of Conversational Implicature Instruction on Developing TEFL Students' Pragmatic Competence and Language Proficiency
}

\begin{abstract}
Ahmed M. M. Abdelhafez
Minia University, Minia, Egypt

The current study aimed at investigating the effect of training undergraduate teaching English as a foreign language (TEFL) students in interpreting conversational implicatures on developing their pragmatic competence and language proficiency. The instruments of the study included a test of pragmatic competence and a test of language proficiency. The findings of the study revealed the effect of explicit instruction in conversational implicatures on developing TEFL students' pragmatic competence and language proficiency. The findings also revealed a significant positive correlation at the level of 0.730 between the participants' pragmatic competence and language proficiency. The findings were discussed in light of previous literature and contextual factors and implications for English as foreign language (EFL) classroom pedagogy were highlighted.
\end{abstract}

Keywords: conversational implicature, teaching English as a foreign language (TEFL) students, pragmatic competence, language proficiency, pedagogical implications

\section{Introduction}

Considerable attention has been recently given to the teach ability of pragmatics (Murray, 2011; Rose, 2005), particularly to the value of explicit teaching of pragmatic theory in classroom settings (Blight, 2002; Lee, 2002). Eslami and Eslami-Rasekh (2008) supported the definition of learners' pragmatic competence as "the ability to use the language to express a wide range of functions as well as interpret their illocutionary force in discourse according to the socio-cultural context in which they are used" (p. 178). Garcia (2004) highlighted the difference between processing linguistic meaning and processing pragmatic meaning. Whereas the learners focus on linguistic information, such as vocabulary and syntax in the former, they focus, in the latter, on contextual information which express the speaker's attitudes and feelings using indirect utterances that must be inferred by the hearer. The current study aligns with other studies that focused on explicit teaching of pragmatics (e.g., Murray, 2011) to non-native teaching English as a foreign language (TEFL) students and attempts to explore some implications for theory and practice.

The importance of conversational implicatures in expressing a message indirectly is well-established (Bouton, 1994). Conversational implicatures are dealt with in Grice's pragmatic theory, which is considered a theoretical underpinning for pragmatics research. Murray (2011) highlighted that Gricean theory could be an accessible framework for accessing and approaching second language (L2) learners' experienced difficulties in

Ahmed M. M. Abdelhafez, Ph.D., lecturer, Department of Curriculum and Instruction, Faculty of Education, Minia University. 
inferring indirect or non-literal speaker meaning. At the heart of Gricean theory of pragmatics is the cooperative principle, which Grice (1975) defined as "Make your conversational contribution, such as is required at the stage it occurs by the accepted purpose or direction of the talk exchange in which you are engaged" (p. 45). He identified four maxims to guide a speaker's contribution in conversation to achieve the cooperative principle. These are:

1. Quantity: Information provided is of an appropriate amount;

2. Quality: Information has adequate evidence to be believed as true;

3. Relation: Information is relevant to the topic;

4. Manner: Information is said in a way that does not set out deliberately to confuse.

A speaker may not observe these maxims accidently (infringement) or deliberately to create an implicature that is to be noticed by hearer. Implicatures are created by speakers to convey various communicative effects (such as irony or understated negative evaluation). The hearer is expected to notice that the maxim has been breached, consider why this is the case, and infer the intended meaning together with any other information that can be retrieved from the way in which it was conveyed. Inability to notice implicatures will result in various forms of pragmatic failure and miscommunication. Murray (2011) pointed out that all communications take place on multiple levels simultaneously and that there is always a potential for unintended (or at times) deliberate mismatches between a speaker's meaning and a hearer's understanding.

There is a need to examine the role of pragmatic instruction in supporting non-native speakers (NNS) of English to understand and interpret conversational implicatures. Bouton (1994) stated that "Little attempt is made in the English as a second language (ESL)/English as a foreign language (EFL) classroom to make learners aware of implicature as a tool of communication or to give them practice at using it in English" (p. 157). This is, in spite of the fact that learners with different cultures experience, difficulty understanding implicatures that have been routinely communicated in the English speaking environment (Bouton, 1988). Although pragmatic competence is part of the knowledge base of teaching English to speakers of other languages (TESOL) professionals, little attention is usually given to pragmatics in teacher education (Vásquez \& Sharpless, 2009). Eslami and Eslami-Rasekh (2008) asserted that teacher education program neither focus on pragmatic aspects of language, nor train the teacher candidate in teaching pragmatic dimensions of language. Garcia (2004) asserted the need for research on pragmatic comprehension to understand this important component of communicative competence.

\section{Literature Review}

Relevant previous studies were reviewed with regard to the effect of explicit teaching of implicatures on developing pragmatic competence and language proficiency as well as the relationship between pragmatic competence and language proficiency. Bouton (1994) investigated the extent to which non-native English speaking international students could interpret conversational implicatures compared to native speakers and the effect of explicit instruction on developing NNS' ability to interpret conversational implicatures of various types. The participants took a test of conversational implicatures in American English. They were asked to choose the correct interpretation from four alternatives following each dialogue. The findings revealed that the non-native students performed significantly poorer than native speakers. They also revealed that non-native learners of English achieved progress in interpreting conversational implicatures after explicit instruction.

Adopting a quasi-experimental, pre/post-test design, Eslami and Eslami-Rasekh (2008) investigated the 
effect of pragmatic instruction on developing EFL learners' language competence in general and pragmatic competence in particular. The participants were 25 master of art (MA) students studying teaching English as a second language (TESL) at Najafabad Azad University in Iran. The findings revealed that explicit pragmatic instruction by providing input enhancement in the L2 classroom, raising L2 learners' awareness about the input features, and engaging students in productive class activities and language use precipitated and facilitated TESL students' pragmatic development to a considerable degree. Eslami and Eslami-Rasekh's study raises awareness of the importance to equip EFL professionals with pragmatic competence as part of their teacher education as well as the importance of teaching pragmatics in the ESL/EFL classroom.

Murray (2011) explored the ways of developing the pragmatic competence of 11 NNS teachers in order to facilitate their work as primary and secondary school English for speakers of other languages (ESOL) teachers in Australia. Her study was mainly qualitative and used a multiple choice inference task consisting of 10 questions to train the participants in interpreting conversational implicatures through a nine 3-hour-session pragmatic training program. She found that the overall success rate for the group in doing the task was $56 \%$. However, the teachers were readily able to apply their understanding of Gricean pragmatics to a post-hoc analysis of their responses to the task of inferring conversational implicatures. Murray's study draws attention to the pedagogical implications of training ESOL teachers in pragmatic competence.

Farahian, Rezaee, and Gholami (2012) investigated the effect of direct instruction of developing 64 intermediate university EFL students' pragmatic competence. Adopting a pretest-posttest design with a treatment group and a control group, data were collected by means of a written discourse completion test as well as self-report. The findings revealed that the instructional intervention resulted in gain in L2 pragmatic ability of the experimental group. The author implied that L2 learners' pragmatic competence development is a prerequisite for the development of communicative competence. They highlighted the role of L2 teachers in fostering pragmatic competence among their learners.

Tuan (2012) attempted to investigate the effect of explicit teaching of conversational implicatures on developing 40 Taiwanese college EFL learners' pragmatic competence and the relationship between the learners' pragmatic competence and language proficiency. The instruments included a web-based implicature test and a Test of English for International Communication (TOEIC) test. The instruction lasted for 10 weeks. The findings revealed a statistically significant difference in the learners' implicature competence in favor of the post-test as well as a positive correlation $(r=0.82)$ between the learners' implicature competence and English language proficiency. The researcher highlighted the necessity of direct or guided instruction in implicature to equip the learners with pragmatic competence.

To investigate the relationship between language ability level and comprehension of implicature, Roever (2001) conducted a study on 181 German high school students, 25 Japanese college students in Japan, 94 ESL students at an American university, and 14 native speakers. The participants were asked to select one of four answer choices that accurately conveyed the meaning of the implied utterance. The findings revealed a positive correlation with ability levels. In the same vein, Cook and Liddicoat (2002) compared the abilities of English language learners with high proficiency and low proficiency to understand linguistic knowledge and contextual knowledge. They found that low proficiency learners focused mainly on interpreting linguistic information relying on bottom-up processing. They failed to understand contextual information. On the other hand, high proficiency learners were able to understand both linguistic and contextual knowledge, and achieved higher levels of language processing automaticity. 
Based on her study on 15 Korean NNS of English with high language proficiency to investigate their ability to interpret conversational implicatures as compared to 15 native speakers of English, Lee (2002) found that high proficiency of English influenced the accuracy of pragmatic comprehension. She suggested that high language proficiency would facilitate the non-native learners' ability to derive the same meaning from conversational implicatures as native speakers. With a similar focus, Taguchi (2005) investigated whether L2 proficiency affects pragmatic comprehension, namely, the ability to comprehend implied meaning in spoken dialogues. Participants included 46 native English speakers at a United States (U.S.) university and 160 Japanese students of English in a college in Japan who were at different L2 proficiency levels. They took a 38-item computerized listening task measuring their ability to comprehend conversational implicatures of different types. The results of the study revealed a significant L2 proficiency influence on accuracy of comprehension.

The previously-reviewed studies highlight the role of explicit instruction in conversational implicatures in developing EFL learners' pragmatic competence and language proficiency. They also highlight the relationship between language proficiency and ability to interpret conversational implicature. According to Kondo (2008), pragmatic instruction sensitizes learners to cultural differences and variables involved in language use. The current study aligns with this view and aims to create a level of awareness through which the participants could be more cognizant of implicatures and more able to notice the relationship between language choices and the effectiveness of communication as highlighted by Takahashi (2005). Pragmatic competence is undertaken as a part of a broader program to prepare TEFL students for the workplace. TEFL students are expected to be able to comprehend the meanings implied in conversational implicatures and communicate these meanings to their prospective learners. The current study attempts to find out whether training TEFL students in inferring conversational implicatures could develop their pragmatic competence and language proficiency by helping them recognize and interpret different types of implicatures. The study seeks to prepare participants to avoid pragmatic failure and to be ready for the intercultural communication needs which they would face on starting their work as EFL teachers.

\section{Context of the Study}

Understanding conversations in the target language represents a challenge to EFL learners. The problem is exacerbated when the conversations are embedded with implied meanings. The researcher observed the difficulties TEFL students face in understanding and interpreting conversational implicatures while teaching an advanced conversation course to fourth-year TEFL students in one of Egypt's state universities. To dig deep into the extent of the problem, the researcher administered a pre-test of pragmatic competence to find out about the participants' ability in understanding conversations in the target language. Their average score percentage was as low as $44.5 \%$. This motivated the researcher to train the participants in conversational implicatures to develop their ability to understand implied meanings in EFL conversations and ultimately to develop their ability to communicate in the target language. TESOL professionals urgently need to understand implicature to avoid pragmatic failure. Pragmatic competence training, an integral component to initial teacher preparation programs, could enlighten prospective teachers about the role of linguistic and cultural factors underlying conversation. They need to be well-equipped for their future career as EFL teachers who are expected to help their prospective pupils achieve successful communication as well. 


\section{Questions of the Study}

The questions of the current study are the following:

1. What is the effect of training TEFL students in conversational implicatures on developing their pragmatic competence?

2. What is the effect of training TEFL students in conversational implicatures on developing their language proficiency?

3. What is the correlation between TEFL students' pragmatic competence and language proficiency?

\section{Hypotheses of the Study}

The hypotheses of the current study are the following:

1. There is a statistically significant difference between means of scores obtained by the participants in the pre/post-measurements of the test of pragmatic competence favoring the post-test;

2. There is a statistically significant difference between means of scores obtained by the participants in the pre/post-measurements of the language proficiency test favoring the post-test;

3. There is a statistically positive correlation between the participants' pragmatic competence and their language proficiency.

\section{Research Design}

The current study adopts the quasi-experimental pre/post-test one group design to test the first and second hypothesis. In addition, the Pearson correlation coefficient is used to verify the third hypothesis. The study also draws on the interpretive paradigm to describe and interpret the participants' responses to the test of pragmatic competence taking into consideration the context of the study and relevant literature.

\section{Participants}

The sample of the study consisted of 31 undergraduate TEFL students at the Faculty of Education in one of Egypt's state universities studying a course in advanced conversation. The researcher was course instructor and delivered the instructional activities.

\section{Instruments of the Study}

Instruments of the study were two tests: the test of pragmatic competence and the TOEIC test. The test of pragmatic competence consisted of 20 multiple-choice items measuring ability to interpret non-literal utterances in American English, to be completed in 30 minutes. The test was developed by Tuan (2012) and was based on Bouton's work (1999). One item of the test was replaced with a new one to suit the mode of applying the test. The test items were deliberately chosen, because there already existed a literature on their use, and the test items had been extensively trialed and validated (Bouton, 1999; Murray, 2011). The preferred multiple choice responses had originally been developed on the basis of actual native speakers (NS) interpretations of speakers' meaning in a set of scenarios, while the distractors were adapted from the most common NNS "incorrect" answers.

The TOEIC test was used in the current study to measure the participants' language proficiency and consisted of two parts: listening comprehension and reading comprehension. In the listening test, the participants were asked 100 items in four sections to demonstrate how well they understood spoken English. The entire listening test lasted for 45 minutes. In the reading test, the participants were required to answer 
several types of reading comprehension questions based on reading a variety of texts. The reading test consisted of 100 multiple choice items in three parts and lasted for 75 minutes. The test was based on Edmunds and Taylor's (2007) TOEIC. As emphasized by Schedl (2010), the test has been widely recognized as a worldwide standard in the assessment of international English use.

\section{Materials}

The training material consisted of mini-conversations representing the four maxims of the Gricean model (flouted). The participants were expected to recognize and interpret the implicatures individually and in groups. As a part of out-of class study, the participants were given a group assignment to submit at least 50 formulaic expressions and their interpretations. The aim of this activity was to familiarize the participants with the implied meanings of what is being said.

\section{Procedures}

The instructional activities of the course were presented following Blight's (2002) four-stage-classroom procedure for explicit instruction in conversational implicature. These four stages were: (1) theory presentation; (2) Gricean analysis of a model conversation; (3) interpretations of implicatures in the model conversation; and (4) group interactions of a range of social interactions. Activities were designed to familiarize the participants with pragmatic theory and to evaluate the impact of the prior awareness-raising sessions on ability to infer implicature, to provoke discussion and to allow participants to become more aware of individual areas of potential communicative difficulty. The Gricean framework was the tool that helped elicit the participants' responses and reflections and their underlying linguistic and cultural factors related to the use of conversational implicatures.

The choice of the Gricean model of implicature is justified in terms of the intercultural learning of TEFL participants who have access to native culture and are learning about the target one. The participants were also asked to explain the main elements of the Gricean model to make sure they understand the new concepts. The activities also consisted of items covering breaches of the four Gricean maxims. These activities included open-class discussion of real-life communicative events in which an implicature would be created and/or inferred. During classroom discussion, the participants were asked to infer and interpret (in pairs and groups) a set of conversations with various types of implicature. They were trained in how to flout a conversation. They were also asked to write scenarios of conversations representing the various kinds of conversational implicatures, i.e., quality, quantity, relation, and manner. Some activities focused on raising cultural awareness that is associated with the use of conversational implicatures.

The participants were invited to reflect on the reasons for their responses while inferring implicatures as well as the obstacles that stood in the way of their attempt to infer and/or interpret implicatures. Class discussion also dealt with the reasons why some items had proven to be difficult. The participants were also asked to write their ideas and reflections on cultural attitudes to the use of implicatures with particular reference to the Egyptian cultural patterns of implicature use. They were also given a context inference activity, in which they were encouraged to use the conversations provided to infer the experiential and cultural context in which the conversations occurred.

\section{Duration of Training}

The training program took place while the researcher was teaching a conversation course to the 
participants. It occurred in 12 four-hour sessions over a period of three months during the first term of the academic year 2013/2014. This is in addition to two sessions for administering pre-tests and post-tests.

\section{Data Analysis}

Data consisted of the participants' responses to the pre/post-tests. The data were analyzed using Statistical Packages for Social Sciences (SPSS). The $t$-test was used to compare means of scores of the participants in pre/post-measurements of the test of pragmatic competence and the language proficiency test. Pearson correlation coefficient was used to measure the correlation between the participants' pragmatic competence and language proficiency.

\section{Results}

Based on quantitative data analysis using $t$-test and Pearson correlation, all three hypotheses of the study were confirmed. As for the first hypothesis, the $t$-test results revealed a statistically significant difference at the level of 0.05 between means of scores obtained by the participants in the pre/post-measurements of the test of pragmatic competence favoring the post-test. This means that the first hypothesis is accepted. Table 1 below presents the $t$-test results:

Table 1

The T-Test Results of the Pragmatic Competence Test

\begin{tabular}{lllllll}
\hline & $t$ & $d f$ & Sig. (2-tailed) & Mean difference & Std. deviation & $\frac{95 \% \text { confidence }}{n}$ \\
\hline Pre-test & 16.68 & 30 & 0.000 & 8.90 & 2.97 & Lower \\
Post-test & 25.85 & 30 & 0.000 & 13.38 & 2.88 & 12.31 \\
\hline
\end{tabular}

It is evident from the table above that the participants' pragmatic competence improved with an increasing mean score of 4.48. This result is similar to that of Tuan (2012) who found that after training her students in conversational implicatures for 10 weeks, their pragmatic competence improved with an increasing mean score of 4.4 .

As for the second hypothesis, the $t$-test results revealed a statistically significant difference at the level of 0.05 between means of scores obtained by the participants in the pre/post-measurements of the language proficiency test favoring the post-test. This means that the second hypothesis is accepted. Table 2 below presents the results of $t$-test:

Table 2

The T-Test Results of the Language Proficiency Test

\begin{tabular}{lllllll}
\hline & $t$ & $d f$ & Sig. (2-tailed) & Mean difference & Std. deviation & $\frac{95 \% \text { confidence }}{\text { Lower }}$ \\
\hline Pre-test & 22.40 & 30 & 0.000 & 57.77 & 14.35 & 52.50 \\
Post-test & 37.84 & 30 & 0.000 & 75.29 & 11.07 & 71.22 \\
\hline
\end{tabular}

As for the third hypothesis, a statistically significant positive correlation was found between the participants' pragmatic competence and their language proficiency. The Pearson correlation coefficient was 0.730 . Table 3 below presents the Pearson correlation results: 
Table 3

Pearson Correlation Results

\begin{tabular}{llcc}
\hline & & Post-test proficiency & Post-test implicature \\
\hline \multirow{3}{*}{ Post-test of proficiency } & Pearson correlation & 1 & $0.730^{* *}$ \\
& Sig. (1-tailed) & - & 0.000 \\
& $N$ & 31 & 31 \\
\hline \multirow{3}{*}{ Post-test of pragmatic competence } & Pearson correlation & $0.730^{* *}$ & 1 \\
& Sig. (1-tailed) & 0.000 & - \\
\hline
\end{tabular}

Note. ${ }^{* *}$ Correlation is significant at the 0.01 level (1-tailed).

It is obvious from the last finding that pragmatic competence correlates positively with language proficiency. This finding resonates with previous studies. For example, Lee (2002) found that high language proficiency facilitates the learners' ability to interpret implicatures. Similarly, Tuan (2012) found that the learners' pragmatic competence positively correlated with overall language proficiency $(r=0.82)$ suggesting that a learner's pragmatic competence is a crucial element to predict one's language proficiency.

\section{Discussion}

The current study aimed to investigate the effect of explicit instruction of conversational implicatures on developing TEFL students' pragmatic competence and language proficiency. The findings revealed a significant impact of instruction in the improvement of the participants' pragmatic competence and language ability. It is echoed in previous literature that formal instruction is an effective approach to develop non-native students' proficiency in interpreting implicatures (Bouton, 1994; Broersma, 1994; Rose, 2005; Takimoto, 2006; Felix, 2008). The findings of the current study also revealed a positive correlation between the students' pragmatic competence and language proficiency, a finding that was supported by previous literature (Roever, 2001; Lee, 2002; Taguchi, 2005; Tuan, 2012).

The participants' ability improved in recognizing and interpreting conversational implicatures representing the four maxims in the Gricean model, especially those related to quantity and quality. The analysis below sheds light on items of the test of pragmatic competence by showing examples of breaching the various types of the Gricean maxims (quantity, relation, quality, and manner). The analysis draws on descriptive statistics of each test item. It also sets the conversations in the contexts of the previous studies as well as that of the current study. The analysis is divided into four sections with examples of breach of each one of the four maxims.

\section{Flouting the Maxim of "Quantity"}

The implicature in item 6 is conveyed, when a person is asked directly for an opinion about a person, object, or action that they do not like, and not wishing to criticize directly, they reply with a favorable comment about a non-central attribute.

6. Jose and Tanya are professors at a college. They are talking about a student, Mark.

Jose: How did you like Mark's term paper?

Tanya: Well, I thought it was well typed.

(Narrator) How did Tanya like Mark's term paper?

a. He liked it; he thought it was good.

b. He thought it was important that the paper was well typed. 
c. He really had not read well enough to know.

d. He did not like it.

The participants' ability to recognize and interpret understated negative evaluation improved at a highly significant level. The percentage of participants who chose the expected answer, choice c, increased from 3.8\% in the pre-test to $88.9 \%$ in the post-test. This highly significant improvement indicates the positive effect of pragmatic training on the participants' ability to interpret understated negative evaluation. Initially, the majority of participants $(77 \%)$ who chose distractors $\mathrm{a}$ and $\mathrm{b}$ in the pre-test could not distinguish between what was important (i.e., the content of the student's term paper) and what is less important (the typing and what makes a paper good). It also indicates that training in conversational implicatures is particularly effective in developing pragmatic competence, with regard to recognizing and interpreting understated negative evaluation for the research group.

A similar finding regarding the improvement in the participants' ability in understanding understated negative evaluation is also evident in the implicature in item 7.

7. Toby and Ally are trying the new buffet restaurant in town. Toby is eating something, but Ally can not decide what to have next.
Ally: How do you like what you are having?
Toby: Well, let us just say it is colorful.
(Narrator) What does Toby probably mean?
a. She thinks it is important for food to look appetizing.
b. She thinks food should not contain artificial colors.
c. She wants Ally to try something colorful.
d. She does not like her food much.

The majority of participants (70.4\%) chose the expected answer, choice d, in the pre-test, compared to $34.6 \%$ of the participants in the post-test. This item highlighted the cultural variations in interpreting implicature. The significance of color in judgment of the quality of food may not be the same in all contexts. To the Western ear, referring to food as colorful, rather than its content (chicken, beef, and vegetables), could be interpreted as mildly derisive; it can hardly be complimentary to imply that the content of food was not identifiable (Murray, 2011). Murray added that the choice of such a culturally ambiguous attribute as a vehicle for the delivery of faint praise introduces an additional layer of complexity to the interpretation. This could explain why the participants did not agree on a specific answer when responding to this item in the pre-test as $19 \%$ of the participants chose distractor a; $15 \%$ of the participants chose distractor $b ; 31 \%$ of the participants chose distractor $\mathrm{c}$; and $34.6 \%$ of the participants chose distractor $\mathrm{d}$, the expected response. The training had a positive impact on reducing the complexity of interpretation of the implied meaning as $70.4 \%$ of the participants chose the expected answer.

Again, in item 16 the majority of participants (77.8\%) correctly interpreted understated negative evaluation and chose the expected answer, choice a, compared to only $11.5 \%$ of the participants in the pre-test.

16. Lee has spent a lot of money on a new suit and he asks his friend, Sandy, about it.

Lee: How do you like my new sweater?

Sandy: It is an interesting color.

(Narrator) What does Sandy mean?

a. She does not like that sweater. 
b. She is interested at the color of that sweater.

c. She thinks it is a bore to discuss that sweater.

d. She thinks Lee is color-blind.

An interesting remark regarding this item of the test is that the vast majority of participants $(80.8 \%)$ incorrectly chose distractor $\mathrm{b}$ in the pre-test. Initially, the participants' interpreted Sandy's remark as the intended meaning. On the surface meaning, they considered the color of the sweater as a decisive criterion. This might be the case in some occasions, but not in the context of this conversation, whereas another factor intervened, i.e., the amount of money spent on the sweater as indicated in the opening utterance. In this case, the price of the sweater is more highlighted than its color. The expected answer was supposed to refer to value for money in terms of material or design, instead of just talking mainly about the color of the sweater which is a subsidiary criterion. During the training program, the participants were sensitized to the role of context and remarks between the lines that provided cues for recognizing implied meanings. The impact of training was evident in the improvement of participants' ability to correctly choose the expected answer. Obviously, the participants decided to look at the deep meaning in conversations, instead of just considering surface meaning as the only criterion for understanding what was said. Thus, they could differentiate between what was said and what was meant.

Non-observance of the maxim of quantity usually takes the form of a violation. In this kind of breach, the speaker intends to conceal the fact that he or she can find nothing more complimentary to say. There may be very different cultural responses to the sanctity of frankness (Wierzbicka, 2003). There are indeed occasions where a polite untruth may be the most appropriate response, but many English speakers would feel compromised, if they breached the maxim of quality with a direct lie. Opportunity for cross-cultural awareness-raising in the classroom context with regard to varying expectations regarding truthfulness and tact is salient here. According to Bouton (1988), understated negative evaluation led to less consistent responses with fewer than $80 \%$ of NS giving the expected answer. Findings of the current study revealed that the participants benefited greatly from training in recognizing and interpreting understated negative evaluation. This improvement, as echoed in the literature, highlights the role explicit pragmatic teaching could have in developing the ability to interpret implicature, even for NS groups (Bouton, 1994, 1999; Murray, 2011).

\section{Flouting the Maxim of "Relation"}

Implicatures related to the maxim of relation were found to be the easiest for both NS and NNS groups (Bouton, 1988). This could be true for the current study. The participants' scores in the pre-test were higher than that of any other maxim. One interesting remark relates to item 5 displayed which represents the certainty issue. The participants' scores in the post-test were lower than those of the pre-test.

5. Jack is talking to his housemate Sarah about another housemate, Frank.

Jack: Do you know where Frank is, Sarah?

Sarah: Well, I heard music from his room earlier.

(Narrator) What does Sarah probably mean?

a. Frank forgot to turn the music off.

b. Frank's loud music bothers Sarah.

c. Frank is probably in his room.

d. Sarah does not know where Frank is. 
In item $5,88.5 \%$ of the participants chose the expected answer, choice c, in the pre-test; whereas, in the post-test, the percentage of those who chose the expected answer decreased to $70.4 \%$. Murray (2011) provided a useful insight that could explain this unexpected finding. When the speaker commences the utterance with a hedging "well," it could be taken as an indication of the possibility of ignorance, which points to a clash of maxims. If the speaker has genuine doubts about the status of her knowledge, she may be choosing to deliberately flout the maxim of relation, rather than risk breaching the maxim of quality. Without any phonological evidence of the manner in which "well" is said, it becomes difficult to distinguish between these two possibilities. According to item 5, about a third of the participants chose distractor $\mathrm{d}$ in the post-test, which was not their preferred option in the pre-test. Perhaps, as a result of training in pragmatic competence, the participants became more aware of the risk of loss of face that may be experienced when a speaker oversteps the boundary of certain knowledge. Although this is a sort of interference due to training, it does not undermine the benefits of pragmatic training in facilitating understanding of other test items and implicatures.

Flouting the maxim of relation provided a useful opportunity for crystallizing cross-cultural insights, and an entry into a review of the language of mitigation and hedging. Keenan (1976) maintained that there are cultural variations in the amount of certainty required before a piece of information can be directly stated. Obviously, some participants became more careful about the issue of certainty than about admission of ignorance, which represents a radical cultural change of attitude.

\section{Flouting the Maxim of "Quality"}

As for the maxim of quality, the training had a significant effect as well. According to the findings, the participants' ability to understand and interpret violations of the maxim of quality improved significantly. They understood irony behind the literal meaning. An obvious example is item 11.

11. At a recent party, there was a lot of singing and piano playing. At one point, Matt played the piano while Brian sang. Jill was not at the party, but her friend Linda was.

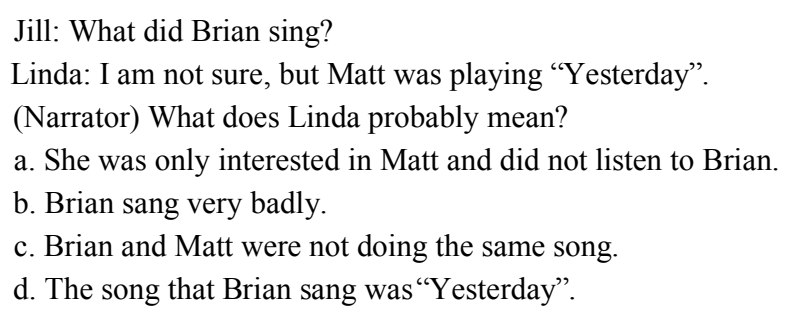

The majority of participants (81.5\%) chose the expected answer, choice b, in the post-test compared to only $3.8 \%$ who chose it in the pre-test. Obviously, Linda did not like Brian's singing. If he sang well, she would pay attention to his singing. Instead, she was attracted to piano playing by Matt. Mentioning the name of the song at the end of her answer indicated that Linda actually knew what Brian sang. Yet, she refused to give the usual answer implying that she did not like the singing. In the pre-test, half of the participants chose distractor a, which means that they only considered the surface meaning of Linda's answer. Only $11.1 \%$ chose this distractor in the post-test. Avoiding distractor a means that the participants were concerned more with what was meant rather than what was said. Additionally, they might become aware that distractor a is an inappropriate violation of the maxim of quality. It was not true that Linda did not listen to Brian as long as she was there during the singing. 


\section{Flouting the Maxim of "Manner"}

With regard to the maxim of manner, the training was also effective. The findings indicate that the participants' ability to understand and interpret breaches of the maxim of manner improved. For example, in item 17 of the test of pragmatic competence, $63 \%$ of the participants chose the expected answer, choice c, in the post-test compared to $26.9 \%$ who chose it in the pre-test.

17. Tom and Jennifer are taking a course together. Tom asked Jennifer about her feelings about the class.

Tom: Do you like linguistics?

Jennifer: Well, let us just say I do not jump for joy before class.

(Narrator) What does Jennifer probably mean?

a. She likes the course very much.

b. She hates the course.

c. She is not very sure about her feelings about the course.

d. She wants to leave the course.

In the pre-test, half of the participants incorrectly chose distractor a. In the post test, only $14.8 \%$ chose it. In addition, the number of participants who chose the expected answer increased. This indicates the improvement of the participants' ability to decipher ambiguity. Perhaps the participants thought that Tom asked Jennifer about her feelings about the class, and she said she did not celebrate each class with such a leap into the air. The response is relevant, but it is a kind of cryptic and they both know it. There must be a reason for that. Perhaps the lack of a straightforward response is a result of the complicated nature of her true feelings. Maybe she likes some aspects about the class, but not everything. Maybe she likes the content but not the instructor. This might be a warning to drop the subject, unless Tom wants to get into an in-depth conversation.

An additional impact of the training program was also achieved. It was noticed from the findings that the participants' ability to avoid the least suitable distractor improved as in item 3 below.

3. Linda and Ally are having lunch at the campus cafeteria.

Linda: The Beetles are coming this Saturday.

Ally: I have two term papers due next Monday.

(Narrator) What does Ally mean?

a. He thinks Linda will help him write his term papers.

b. He has no ideas about who the Beetles are.

c. He wants to discuss the Beetles in his term papers.

d. He is unable to go the Beetles show with Linda.

In item 3, 23.1\% of the participants chose distractor a in the pre-test. This distractor is obviously the least expected response. However, in the post-test, the percentage of participants who chose the same distractor decreased to only $3.7 \%$. This could be attributed to the effect of training. The opposite happened to distractor $b$. Initially, it was avoided by the participants, in spite of being closer to the expected answer than choice a. However, in the post-test, more students chose it. The choice of distractor b could be interpreted in light of Ally's degree of certainty. Given that Ally might be unaware of who the Beetles are, she resorted to changing the subject to avoid being seen as ignorant or uncertain.

\section{Pedagogical Implications}

Ability to recognize and interpret conversational implicatures could inform and enhance teaching (Murray, 
2011). Daily classroom interaction between the teacher and students and between students and other students depend on conversation. Successful conversations in the classroom will result in effective communication. Farahian et al. (2012) highlighted that pragmatic competence development is a pre-requisite for the development of communicative competence. Thus, the use of conversational implicatures is inevitable for effective communication to take place. Conversational implicatures could be used to serve a variety of communicative purposes. Certain language functions, such as irony, are only carried out effectively through implicatures. This means that learners, especially advanced ones, need to be trained in using them. Fostering pragmatic competence among EFL learners could be one of the L2 teacher roles (Farahian et al., 2012).

Implicatures of various types can be implemented for classroom application. Relation implicatures are relevant to the silly questions asked by the students, which may push the teacher to change the subject or use Pope questions as a response. This type of implicature can be also used to explain to the students how ideas can go off-topic and refocuses the learners' attention to what needs to be achieved. The teacher's response to students' questions may influence classroom interaction. A teacher's utterance in response to a student's silly question may hurt that student's feelings and intimidate learners. Murray (2011) argued that the teacher's inability to distinguish between an utterance that is gently cajoling or bitingly sarcastic can have a long term negative impact on teacher-student and other workplace relationships. She further added that generating a set of obvious or "silly" questions that a teacher might be asked, recording spontaneous verbal responses, and then exploring the match between speaker intent and both the lexicogrammatical and phonological features of their rejoinders could provide the opportunity for those students to notice and possibly pre-empt serious pragmatic failure.

Quality implicatures can also be used in the classroom, especially during the meaningful and communicative practice stages of the EFL lesson. Manner implicatures can also have a place in the classroom. Ambiguity is normal in the EFL classroom due to language limitations. This always results in communication failure. Training the learners in how ideas and conversations can be carried out clearly or vaguely can provide good opportunities for recognizing and avoiding ambiguity. Quantity implicatures could be implemented while conducting controlled versus free practice. This is obvious while learning EFL, as learners usually say less than what is required. This is because of language limitations. Thus, learners violate the cooperative principle and could be considered as lacking communicative ability.

Target and cross-cultural awareness-raising is part and parcel of the EFL curriculum. Various opportunities emerge while teaching language skills and language aspects that may involve cultural references that are ambiguous to learners. The use of conversational implicatures as an activity is a good approach to achieve this. Specific programs for EFL talented learners could involve the use of figurative language while speaking and writing. These programs could be built around how to recognize and interpret as well as to use conversational implicatures. They can also involve when and with whom these learners can use implicatures. Inability to recognize and interpret implicatures could represent a source of demotivation for EFL leaners and have a negative impact on their sense of self-efficacy while learning EFL. Responses (such as Pope questions) which incorporate an implicit appraisal of the question are not uncommon in classroom contexts.

\section{Conclusion}

The findings of the current study revealed the effect of instruction in conversational implicatures on developing TEFL students' pragmatic competence and language proficiency. They also revealed a positive 
correlation between the participants' pragmatic competence and language proficiency. Research needs to be continued in the fertile area of pragmatics and its role in classroom pedagogy. A study may explore the effect of pragmatic instruction on developing learners' understanding of when, why, and with whom a person chooses to speak ironically. Another study may evaluate the application level of EFL student teachers' pragmatic competence in their own teaching. Murray (2011) highlighted that ethnographic research would extend knowledge of implicature in the classroom and help identify instances in which both teachers' and students' lack of pragmatic competence leads to communication breakdown. Future research agenda may also include the facilitative role of multimedia resources in reducing ambiguity. A study may examine the effect of using audio and video conversations on developing pragmatic competence.

\section{References}

Blight, R. (2002). Classroom procedure for explicit instruction in conversational implicature. Paper presented at The JALT Conference Proceedings. Retrieved from http://jalt-publications.org/archive/proceedings/2002/142.pdf

Bouton, L. F. (1988). A cross-cultural study of ability to interpret implicatures in English. World Englishes, 17(2), 183-196.

Bouton, L. F. (1994). Conversational implicature in the second language: Learned slowly when not deliberately taught. Journal of Pragmatics, 22, 157-167.

Bouton, L. F. (1999). Developing non-native speaker skills in interpreting conversational implicatures in English: Explicit teaching can ease the process. In E. Hinkel (Ed.), Culture in second language teaching and learning. New York, N.Y.: Cambridge University Press.

Broersma, D. (1994). Do chickens have lips? Conversational implicative in the ESL classroom. Paper presented at The 8th Annual Meeting of the International Conference on Pragmatics and Language Learning, Urbana, I.L..

Cook, M., \& Liddicoat, A. J. (2002). The development of comprehension in interlanguage pragmatics: The case of request strategies in English. Australian Review of Applied Linguistics, 25, 19-39.

Edmunds, P., \& Taylor, A. (2007). Developing skills for the TOEIC test. Compass Publishing. ISBN: 978-1-59966-086-8.

Eslami, Z. R., \& Eslami-Rasekh, A. (2008). Enhancing the pragmatic competence of non-native English-speaking teacher candidates (NNESTCs) in an EFL context. In E. A. Soler \& A. Martínez-Flor (Eds.), Investigating pragmatics in foreign language learning, teaching, and testing (pp. 178-197). Bristol: Multilingual Matters.

Farahian, M., Rezaee, M., \& Gholami, A. (2012). Does direct instruction develop pragmatic competence? Teaching refusals to EFL learners of English. Journal of Language Teaching and Research, 3(4), 814-821.

Félix-Brasdefer, J. C. (2008). Teaching pragmatics in the classroom: Instruction of mitigation in Spanish as a foreign language. Hispania, 91(2), 479-494.

Garcia, P. (2004). Pragmatic comprehension of high and low level language learners. The Electronic Journal for English as a Second Language, $8(2)$.

Grice, H. P. (1975). Logic and conversation. In P. Cole \& J. L. Morgan (Eds.), Syntax and semantics (pp. 41-58). New York, N.Y.: Academic Press.

Keenan, E. O. (1976). The universality of conversational postulates. Language in Society, 5(1), 67-79.

Kondo, S. (2008). Effects on pragmatic development through awareness-raising instruction: Refusals by Japanese EFL learners. In E. A. Soler \& A. Martínez-Flor (Eds.), Investigating pragmatics in foreign language learning, teaching and testing (pp. 153-177). Bristol: Multilingual Matters.

Lee, J. S. (2002). Interpreting conversational implicatures: A study of Korean learners of English. TESOL Korea Journal, 5(1), $1-25$.

Murray, J. C. (2011). Do bears fly? Revisiting conversational implicature in instructional pragmatics. The Electronic Journal for English as a Second Language, 15(2).

Roever, C. (2001). A web-based test of interlanguage pragma linguistic knowledge: Speech acts, routines, and implicatures (Unpublished doctoral dissertation, University of Hawaii, Manoa).

Rose, K. R. (2005). On the effects of instruction in second language pragmatics. System, 33, 385-399.

Sched1, M. (2010). Background and goals of the TOEIC listening and reading test redesign project. Retrieved from ETS Website https://www.ets.org/research/policy_research_reports/publications/report/2010/itjq 
Taguchi, N. (2005). Comprehending implied meaning in English as a foreign language. The Modern Language Journal, 89(4), 543-562.

Takahashi, S. (2005). Noticing in task performance and learning outcomes: A qualitative analysis of instructional effects in interlanguage pragmatics. System, 33(3), 437-461.

Takimoto, M. (2006). The effects of explicit feedback on the development of pragmatic proficiency. Language Teaching Research, $10(4), 393-417$.

Tuan, J. (2012). Does fish swim? Teaching conversational implicatures in the EFL classroom. Online Journal of Shu-te Social Science, 7(2), 77-100.

Vasques, C., \& Sharpless, D. (2009). The role of pragmatics in the master's TESOL curriculum: Findings from a nationwide survey. TESOL Quarterly, 43(1), 5-28.

Wierzbicka, A. (2003). Cross cultural pragmatics: The semantics of human interaction. Berlin, N.Y.: Mouton de Gruyter. 